\title{
Wear mechanisms and wear investigations of dental materials; a review of the literature
}

\author{
Gadeer E. Mukatash Nimri*
}

${ }^{*}$ Corresponding: gadeermukatash@hotmail.com

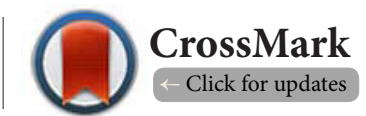

Consultant in prosthodontics, Royal Medical services, Head of the prosthetic department at King Hussein Medical Center, Amman, Jordan.

\begin{abstract}
This is a review of the literature that discuss the different wear mechanisms and methods of investigation of dental materials since these mechanisms have been described as a complex, multi-factorial process. The four main types of wear mechanisms described are; abrasive, adhesive, fatigue, corrosion, as well as several minor types. Wear investigations are also reviewed. Revision is based on both in vivo and in vitro studies in which various methods were used to help in understanding wear resistance of different types of dental tissues and materials and how to reduce the harmful effect of such mechanisms.
\end{abstract}

Keywords: Abrasion, adhesion, fatigue, corrosion, wear

\section{Introduction}

Wear of tooth and restorative material is a common phenomenon in dentistry and occurs when two surfaces undergo slipping movement under an applied load [1]. It can be considered to be either desirable or undesirable depending on the degree of wear and the situation [2]. Correct management of wear requires an understanding of its causal factors [3-5].

Van Noort (1994) [6] defined wear as a process by which material is displaced or removed by the interfacial forces which are generated as two surfaces rub together. According to Harrison (1977) [7] an acceptable definition of wear resistance is that given by the American Society of Testing and Materials viz. "the ability of material to withstand mechanical actions such as rubbing, scraping, or erosion which tend progressively to remove material from its surface".

In fact, wear is a complex, multifactorial process [8], Pugh (1973) [9] stated that this process results from atleast five underlying mechanisms which seldom act in isolation and the progress depends on the structure of the surfaces, the contact stress, and the activity of any lubricating layer, the temperature and the duration of contact. However, the importance of the various factors contributing to wear may be different [10].

Dahl and Oilo (1996) [11] stated that the amount of substance lost and the predominant type of wear are specific for each type of material and depend on its physicochemical properties and its coefficient of friction. Friction determines the energy transfer invoked by a sliding movement along the surface of a body and, in the dental context; this in its turn depends on many factors such as quality of saliva and the contacting body.

Mair (1992) [12] reviewed studies on the wear of dental materials and pointed out that the terms used to define wear have slightly different meanings when used by dental material scientists to describe wear of restorations, compared to when they are used by oral biologists, pathologists, or epidemiologists, to describe clinical manifestations.

Further to this, tribologists (i.e., tribology is the study of friction, lubrication and wear) use the terms in yet another way to describe the underlying mechanisms of wear. In tribology the fundamental wear processes are defined as abrasive wear, adhesive wear, fatigue wear, fretting wear, erosive wear and corrosive wear [9]. However, according to Van Noort (1994) [7] the main types of wear that occur in the oral cavity are abrasive wear (2-body abrasion \& 3-body abrasion), fatigue wear and corrosive wear.

Therefore, the excessive differential wear of dental materials has significant deleterious effects on the biologic, functional, and esthetic condition of the masticatory system. However, controlled investigations of numerous factors that might influence wear of the various dental materials have been mainly in vitro studies, the findings of which might not correlate with clinical experience [13]. In vitro wear studies were mainly concerned of the effects of temperature, cyclic and applied loading, aging, 
lubricant $\mathrm{pH}$ surface coatings and toothbrushing/toothpaste on the wear of dental materials. On the other hands, in vivo studies of wear of dental materials have focused mainly on the effects of abrasive diets and parafunctional habits, acids and toothbrushing/toothpastes on clinical wear of the dental materials $[14,15]$.

The primary purpose of this paper is to give a perspective on our current state of understanding of wear phenomenon. It discusses well-established aspects of wear investigations and those areas which still require further research.

\section{Review \\ Main types of wear Abrasive wear}

Abrasive wear can be defined as the wearing away or removal of material by the act of rubbing, cutting, or scraping [16] and occurs when a rough surface or loose hard particles plough out softer material. Abrasion depends on many factors including, hardness, size and shape of the abrasive, speed of movement of the abrasive and the substrate against each other, pressure applied on the substrate and the amount and type of lubrication between them.

Harrison (1978) [17] has described the wear process that takes place in the mouth as either two or three-bodied wear or combination of both. With only saliva in the system wear is restricted to a two-body process (i.e., between two rubbing surfaces). The introduction of an abrasive such as toothpaste or food produces a three-body situation. Furthermore, brushing any restorative or prosthetic material with a toothbrush and water alone may produce two-body abrasion, while the introduction of a dentifrice may lead to a three-body abrasion or combination of two and three-body abrasion.

\section{Adhesive wear}

Adhesive wear results from friction between the moving surfaces which causes local cold welding between asperities. Further movement of the surfaces fracture these welds and transfer material from one surface to another [12].

\section{Fatigue wear}

Fatigue wear is wear due to the generation of intermittent stresses where the degree of scratching may be minimal [18]. According to Pugh (1973) [9], the term fatigue should be reserved for a situation where there is rolling rather than sliding of surfaces over each other.

\section{Corrosive wear}

Corrosive wear results from the interaction of chemical degradation and movement of the surfaces. The surfaces is weakened by chemical degradation and then removed by rubbing against an opposing surface [12].

\section{Minor types of wear}

Minor types of wear are responsible for about $5 \%$ of the wear experienced in present-day machinery [8]. They can be clas- sified into:

1. Erosion wear caused by high velocity liquid.

2. Impact wear arising repetitive impact of two hardened working surfaces.

3. Other isolated instances of a type of wear.

\section{Method of wear investigation}

Wear testing is one of the most challenging subjects in dental materials science. Laboratory assessments of abrasiveness of the toothpastes date atleast from Miller in 1907 or could be considered as early as Goddard in $1845[19,20]$ and since that time both clinical and laboratory studies have been conducted. However, there is no in vitro method which can completely simulate the oral environment [21] and the lack of precise measuring techniques [22] makes the results of different studies difficult to correlate.

A number of attempts have been made to develop a standard method that could simulate in vivo wear, or atleast give useful comparative data. Early experiments used rotating glass and metals [19]. These were superseded by mechanical devices using weighted toothbrushes and tooth minerals to simulate factors found in tooth brushing. Kesseler (1933) [23], of the American National bureau of standards [23], described a method of determining the wear resistance of natural stone flooring. However, the equipment he used was considered too massive for the study of small objects such as teeth. Beall (1943) [24] attempted to assess the wear of resin teeth on complete dentures by making differential measurements of stone replicas and concluded that wear due to function occurred at an appreciable rate.

Although, in vivo wear studies would seem ideal to evaluate the wear behaviour of dental materials. The complex nature of wear mechanisms of dental materials makes in vivo wear studies time-consuming, expensive and the results scatter widely due to patient and dentist related factors. Most of all, the fundamental problem with the in vivo wear model is that it is impossible to isolate and vary key factors that may influence the wear process $[\mathbf{2 5}, \mathbf{2 6}]$.

Moreover, in vivo wear investigation of dental materials composed of subjective performance assessment of the material using models and then numerical measurement of the various results. Numerous indices have been developed for use in clinical studies and most are based on numerical grades to quantify the amount of hard tissue loss [25-28].

Although many wear studies have been carried out on dental materials they have been predominantly designed to investigate wear similar to that produced by functional movements in vivo. Studies involving the maintenance of prostheses are relatively few in number.

Moreover, surveys carried out to identify the commonest cleaning methods and materials among denture wearers showed that the majority used mechanical cleansing especially brushing using a toothpaste or a combination of mechanical and chemical cleansing methods with toothbrushes with their added abrasive particles being the most popular cleaning mehod used [29]. 
However, the extensive use of mechanical cleansing can often lead to the wear of the denture surface particularly if unsuitable brush used e.g., with hard bristles, an abrasive paste or powder, or an inappropriate brushing technique.

The physical/chemical nature of the denture base may also vary. In addition to 'normal' denture base resins some dentures are constructed from so-called "high impact" resins containing rubber graft co-polymers. Furthermore, over the lifetime of a denture, it may be modified by relining, either in the laboratory using auto-curing poly(methyl methacrylate) resin, or in the clinic using one of the currently available 'in-mouth' curing resins containing higher molecular weight polymers (e.g., poly (ethyl methacrylate) $[\mathbf{1 8 , 2 0}]$. There are therefore a number of possible situations in which interaction between the cleaner and the denture base may produce varying amounts of wear. Therefore the in vitro studies that carried out to determine the potential damage to the denture resins by brushing with a range of oral cleaning pastes using and electric-motor driven, reciprocal-action toothbrushing machine could be a situation that simulate methods normally employed by denture wearers and worthy to review.

\section{Classification of methods}

In general, investigations of the wear in dentistry may involve both in vivo and in vitro studies.

Osborne (1949) [31] classified the available methods for determining abrasion resistance as:

1. Direct abrasion by a rough surface, with or without a lubricant, followed by measurement of loss of weight or change in dimension of the test piece after a given period.

2. Abrasion by a relatively soft substance such as rubber in conjunction with an abrasive agent. However, this method has been criticized because of the difficulty in keeping the abrasive particles between the abrader and specimens throughout the test period.

According to Craig and Powers [2] the testing method used to investigate wear of dental tissues and materials can be summarized as:

1. Service or clinical testing.

2. Simulated service measurements.

3. Model systems using a variety of wear machines.

4. Measuring a related property such as hardness or coefficient of friction.

5. Examining the amount and type of surface failure from a single or low number sliding strokes.

6. Measuring the surface properties of the solid such as Zeta potential is a measure of the electrical double layer at the surface of solid.

These workers emphasized that clinical studies are time consuming, difficult to quantify, and subject to individual variability. On the other hand, they considered that much progress had been made in developing toothbrush abrasion tests, two-body abrasion tests and single and multiple pass tests. Furthermore, they considered that single or a small number of passes permitted better understanding of the actual processes by which wear occurs.

\section{Previous investigations}

A wide range of methods has been used to investigate the wear of dental materials and to attempt the development of a standard method that could simulate in vivo wear, or atleast give useful comparative data. This review is not comprehensive but highlights some of the more relevant methods used.

Slack (1949) [32] reported a method for testing abrasion hardness (as a measure of wear resistance) using a commercial wear tester, the Taber 'Abraser'. This device had a caborundum paper disc, 220 grit that rotated against the specimen under an applied load of $500 \mathrm{gm}$. The specimens were prepared from human natural and artificial (acrylic resin) teeth. The weight loss for a specific number of revolutions was determined as an indication of the abrasive hardness of the specimen.

Sexson and Phillips (1951) [33] studied the effect of various domestic cleansing agents on heat-cured acrylic resin using a motor-driven brushing machine fitted with nylon brushes under a load of $240 \mathrm{gm}$ for a brushing period of 20,000 strokes (equivalent to approximately 2 years of twice daily cleaning). They determined weigh loss, surface loss, and luster change and carried out microscopic examination of the surface.

Dobbs and Abbott (1986) [34] reported a more sensitive method for measuring the abrasievness of cleaning pastes. Tritium-labeled denture-base resin specimens were prepared and subjected to 10000 strokes using a special brushing machine fitted with a nylon toothbrush with extra-hard bristles. Samples of the homogenized slurry from each run had their radioactivity determined in a scintillation spectrometer. The results indicated that most cleaning agents showed decreased abrasivity as the dilution factor was increased. They concluded that this method was sufficiently sensitive to detect differences of abrasivity between different batches of the same brand of dentifrice. Bull et al., (1968) [35] used both in vivo and in vitro assessment methods to study the abrasion and cleaning properties of selected toothpastes. Tooth brushing was simulated using a normal toothbrush, realistic movement and progressive dilution of the abrasive slurry, together with an arbitrarily selected applied load. Specimens were produced from natural tooth enamel and dentine and the measurement of abrasion was conducted by a radiochemical method. The in vivo study was carried out on a number of volunteers and the toothpastes were ranked in a hierarchy relative to each other using a photographic assessment method. The results showed a good agreement between dentine abrasion and cleaning effectiveness. Comparison of the data for abrasivity and cleaning showed good (sic) correlation between the in vitro and in vivo studies.

Heath and Wilson (1976) [36] described a horizontal brushing method for determining toothbrush-dentifrice abrasion of some restorative materials. Their apparatus was designed to allow variations in stroke length and number of stroke, load on the brush, dynamic stiffness of the brushes and it also included temperature control. In an attempt to simulate in vivo conditions 
as closely as possible when conducting this in vitro test, the specimens were abraded at $37^{\circ} \mathrm{C}$ using a $5 \mathrm{~N}$ load, $45 \mathrm{~mm}$ strokes and a brushing rate of 4.5 strokes/s. The slurry baths reciprocated at 5 strokes/s over a distance of $5 \mathrm{~mm}$. A 22\% dentifrice slurry was used and all specimens were subjected to 20,000 brushing strokes (which was considered by these authors to be equivalent to 10 months wear in the mouth, a different value from that suggested by Sexson \& Philips (1951) [33], using another set of three brushes. However, the machine was relatively complex and the moving parts required frequent replacement.

An American Dental Association approved method for the measurement and comparison of the abrasivity of dentifrices was described by Hefferren (1976) [20]. A cross-brushing machine was used to abrade irradiated dentine samples from the roots of extracted permanent human tooth. This method was first described by Grabenstetter et al., (1958) [37] who used the ${ }^{32} \mathrm{p}$ radioactivity removed from the dentine as the index of abrasion.

Harrington et al., (1982) [38] proposed the use of tooth brushing machines as standard method of measuring tooth brush/dentifrice abrasion of the whole range of direct restorative materials. In their study, a single type of brush was used and a dentifrice paste was prepared according to the formula in BS5136: 1981 in which calcium carbonate is prescribed as the abrasive agent. The specimens were subjected to 60.000 strokes at $37^{\circ} \mathrm{C}$. The central line average (CLA) or roughness value $\left(R_{a}\right)$ was determined using a profile measuring instrument and the material loss was calculated from the observed weight loss. In their discussion of the results, these workers pointed out that the abrasive resistance of every bath of material differed from the others. They also found that the surface roughness of some material increased after brushing, while for others it decreased. They reported that the unfilled, self-cured acrylic resin (Sevriton) suffered the greatest reduction in thickness.

Diskson (1979) [39] reviewed a number of studies of the wear of composite and other restorative materials and reported that different methods produced different result. He concluded that further study should be conducted to evaluate the different materials. McCabe and Smith (1981) [40] summarized the result of some of the in vitro methods for measuring wear of restorative materials, viz. Pins and plates, brushes and dentifrices and abrasive wheels. They reported that these methods ranked the materials in a different order from that obtained by clinical tests. All these methods were based on the assumption that 2-body, 3-body or both abrasive mechanisms played a part in the wear process. One method involving specimen vibration in a capsule lined with abrasive paper combined both abrasive wear and fatigue within one experimental system. The degree of wear was measured by weight loss, later converted to volume loss. A linear relationship was found between volume loss and time up to 320 minutes under standardized conditions. McCabe and Smith (1981) [40] concluded that this method could be of value in predicting the wear rate of any restorative material as it have the same ranking order as that from clinical tests.

Atkinson et al., (1982) [41] described the development of a technique for the accurate measurement of wear using dual source laser holography. The laser beam was split by passing it trough a prismatic beam splitter position was adjusted to allow the two divergent beams to cross in the region of the specimen under investigation. Interference contour fringes occurred on the surface. Photographs were taken and measurements were taken pre and post-wear Photographs. Volume loss was calculated using computerized photogrammetry. The accuracy of this technique was claimed to between $2 \%$ and $10 \%$, depending upon the data processing technique used.

Harrison et al., (1984) [22] described the development of an instrument which allowed changes in surface profile to be measured by utilizing $\beta$-particle backscatter. The radioisotope ${ }^{147} \mathrm{Pm}$ was used as the source of $\beta$-particle in conjunction with 2 silicon surface barrier detectors and various precision motion devices, all contained within an evacuated chamber. The method was based on the observation that when a beam of $\beta$-particles impinges on a surface, a proportion are scattered through large angles and re-emerge at the surface. These re-emerge particles can be detected, and thus changes in the profile can be evaluated. An optical microscope was incorporated into the instrument to enable specimen to be accurately repositioned in relation to be the $\beta$-particle beam. This system was capable of detecting changes of the order of $15 \mu \mathrm{m}$ on the profiles of irregular shaped surfaces. It was concluded that this instrument was suitable for studying the wear of a variety of dental materials.

Harrison and Jagger (1997) [42] used an electric-motor driven, reciprocal action, tooth brushing machine to investigate the potential damage to poly (methylmethcrylate) denture bases from five different cleaning pastes. The specimens were made from a commercial heat-cured denture base resin processed using an overnight curing cycle. Brushing was carried out for 5000, 10,000 and 20,000 cycles using medium toothbrushes with a new head being used for each product and dilution run. Surface profilometry was carried out using profile-measuring machine attached to a microcomputer. It was also concluded that the overall abrasivity of pastes was mainly related to the nature of the abrasive agents and their concentration in the pastes.

Schirrmeister et al., (2006) [43] was investigate the clinical performance of a new dental material (Ceram.X) in combination with a new primer-adhesive (K-0127) using modified Ryge's (i.e., pulpitis, sensitivity, recurrent caries, changes in surface texture color stability, Marginal discoloration or integrity). The results shows that after 2 years of clinical service, $96.8 \%$ of the Ceram·X/K-0127 and 100\% of the Tetric Ceram/Syntac Classic restorations were in place and performed clinically well. However, it should be noted that conclusions from an interim analysis such as this should be drawn with some reservation [43].

Reis et al., (2008) [44] evaluate the wear resistance of polymethyl methacrylate (PMMA) denture teeth based on their chemical composition when opposed by a ceramic antagonist. The in vitro two-body wear-testing apparatus used in this study was a simulated brushing machine. Wear resistance was measured as height loss (mm) under $300 \mathrm{~g}$ (sliding force) after 100,000 cycles, 
using a digital measuring microscope. The results showed that the three types of PMMA denture teeth presented significantly different wear resistance against the abraded ceramic. The high-strength PMMA denture teeth were more wear-resistant than the conventional PMMA denture tooth.

Cao et al., (2013) [45] investigated wear resistance and hardness of five kinds of composite resins. Wear volume, hardness and surface structure of each tested material was examined by a three-dimensional non-contact optical profilometer, Vickers indentation technique and scanning electron microscope. They concluded that the use of custom-made machine could be suitable to simulate sliding of an antagonist cusp on an opposing occlusal composite restoration.

It is obvious that there has been progress in understanding the underlying mechanisms and influencing factors of wear of dental materials, it is evident that collaboration among material scientists, tribologists and dentists will help advance the progress of this field of study in the future.

One of the most popular measuring methods of tooth wear is the direct measuring using clinical tooth wear indices [46-50]. However, According to the results of Ohlmann et al., (2008) all metal-ceramic wear studies were subjected to a substantial amount of bais, and additional studies, properly designed to determine bais, were advised [50].

Ekfeldt and Oilo (1990) [51] investigated, in vivo, both quantitative and qualitative aspects of the wear process in relation to some prosthetic materials. Their model combined two methods, removable crowns and a replica technique. Recording of bite-force and analysis of saliva were performed. Wear rate was determined by weighing the removable crown before and after insertion in the mouth and recording the shape with silicone material. Scanning electron microscopy (SEM) was used to analyze the surface appearance of the wear facets. The result showed that all the materials tested showed an increased wear rate when the opposing material was porcelain. In their conclusion these workers pointed out that in vivo wear is a complex phenomenon with many parameters contributing to the process.

In an attempt to quantify wear, an indirect techniques for evaluation of tooth wear were suggested to measuring the loss of tooth surface using cast replicas [51,52].

For more accurate quantification, image analysis, scanning electron microscopy were used [53-55]. Etman et al., (2008) tried to quantitatively measure tooth and ceramic wear over a 2 -year period using a novel superimposition technique. Their results showed that there was a statistically significant difference in the mean depth of wear between all systems [54]. Moreover, the computer graphics (Delong 1989) [56] three dimensional (3D) scanner [57,58] and profilometry [59-61] were developed where enamel, ceramic and metal were tested in vivo. However, an additional studies, properly designed to determine bais, were still advised [43].

Al-Omiri et al., (2010) compared the reliability of three different methods to detect incisal wear over a 6-month period. The methods used were a CAD-CAM laser scanning machine, a tool maker microscope for micromeasurement applications and a conventional tooth wear index (Smith and Knight wear index) [62]. It was found that the tooth wear index was the least sensitive for tooth wear quantification and was unable to identify wear progression in most cases.

Liu (2014) tried to estimate the prevalence of tooth wear in the aging population of northwest China and to investigate the factors associated with such tooth wear using cross-sectional analytic clinical and questionnaire study. They concluded that multiple factors were contribute to different patterns of tooth wear observed, especially the habitual consumption of a hard or sour diet [63].

\section{Conclusion}

"The primary purpose of this paper is to give a perspective on our current state of understanding of wear phenomenon in the dental materials". It can be seen from preceding section that wear is a complex phenomenon and it has been demonstrated that different experimental methods produce different results in term of the ranking of abrasive system. However, perhaps the best way to draw conclusion from single studies or in the comparison of different investigations is to consider the ranking of the tested material within each study.

\section{Competing interests}

The author declares that he has no competing interests.

Publication history

Received: 21 January 2015 Revised: 07 March 2015

Accepted: 13 April 2015 Published: 20 April 2015

\section{References}

1. Sulong, M. Z. and Aziz, R. A. (1990). Wear of materials used in dentistry: a review of the literature. J Prosthet Dent, 63, 342-9.

2. Craig, R. G. and Powers, J. M. (1976). Wear of dental tissues and materials. Int Dent J, 26, 121-33.

3. Suh, N. P. (1977). An overview of the delaminating theory of wear. Wear, 44, 1-16.

4. Smith, B. G. and Robb, N. D. (1989). Dental erosion in patients with chronic alcoholism. J Dent, 17, 219-21.

5. Lee, A., He, L. H., Lyons, K. and Swain, M. V. (2012). Tooth wear and wear investigations in dentistry. J Oral Rehabil, 39, 217-25.

6. Van Noort, R. V. (1994). Introduction to Dental material. London: Mosby, 101-102.

7. Harrison, A. (1977). Clinical and laboratory studies of the abrasion resistance of some dental materials. Ph.D. thesis. University of Wales.

8. Burwell, J. T. (1957). Survey of possible wear mechanisms. Wear, $1,119-141$.

9. Pugh, B. A. (1973). Tribology text for students: Friction and wear. Newnes-Butterworths: London. 141-173.

10.Savabi, O., Nejatidanesh, F., Fathi, M. H., Navabi, A. A. and Savabi, G. (2013). Evaluation of hardness and wear resistance of interim restorative materials. Dent Res J (Isfahan), 10, 184-9.

11.DahI, B. and Oilo, G. (1996). Wear of teeth and restorative 
materials. In: Prosthodontics principles and management strategies. Owal, B., kayser, A. F., Carlsson, G. (Eds). Wolfe: Mosby. 187-200.

12.Mair, L. H. (1992). Wear in dentistry--current terminology. J Dent, 20, 140-4.

13. Oh, W. S., Delong, R. and Anusavice, K. J. (2002). Factors affecting enamel and ceramic wear: a literature review. J Prosthet Dent, 87, 451-9.

14. Kaidonis, J. A., Townsend, G. C. and Richards, L. C. (1992). Abrasion: an evolutionary and clinical view. Aust Prosthodont J, 6, 9-16.

15. Yip, K. H., Smales, R. J. and Kaidonis, J. A. (2004). Differential wear of teeth and restorative materials: clinical implications. Int $J$ Prosthodont, 17, 350-6.

16. Ferracane, J. L. (1995). Materials in dentistry: principle and application. Philadelphia, 293-311.

17. Harrison, A. (1978). Wear of combinations of acrylic resin and porcelain, on an abrasion testing machine. J Oral Rehabil, 5, 1115.

18. Anderson, J. N. (1976). Applied Dental material. 5th. Ed Oxford, Blackwell scientific publications. 291-302.

19. Wright, H. N. and Fenske, E. L. (1937). Relative abrasive properties of the more commonly used dentifrice abrasives. Am Den Ass Jnl and Den Cosmos, 24, 1889-1895.

20. Hefferren, J. J. (1976). A laboratory method for assessment of dentrifrice abrasivity. J Dent Res, 55, 563-73.

21.Stober, T., Lutz, T., Gilde, H. and Rammelsberg, P. (2006). Wear of resin denture teeth by two-body contact. Dent Mater, 22, 243-9.

22.Harrison, A. Moores, G. E. and Glentworth, P. (1984). Measurement of Changes in surface profile due to wear using 174PM ß particle Backscatter technique. I. Instrument development and application to controlled changes in surface profile. Wear, 93, 37-52.

23. Kessler, D. W. (1933). Research paper RP612. Journal of Research of National Bureau of Standards, 11, 3-5.

24. Beall, J. R. (1943). Wears of acrylic resin teeth. J Am Dent Assoc, 30, 252-256.

25. Heintze, S. D. (2006). How to qualify and validate wear simulation devices and methods. Dent Mater, 22, 712-34.

26. Lewis, R. and Dwyer-Joyce R. (2005). Wear of human teeth: a tribological perspective. J Engineering Tribology. 219, 2-19.

27. Bardsley, P. F. (2008). The evolution of tooth wear indices. Clin Oral Investig, 12 Suppl 1, S15-9.

28. Cvar, J. F. and Ryge, G. (2005). Reprint of criteria for the clinical evaluation of dental restorative materials. 1971. Clin Oral Investig, 9, 215-32.

29. Saha, A., Dutta, S., Varghese, R. K., Kharsan, V. and Agrawal, A. (2014). A survey assessing modes of maintaining denture hygiene among elderly patients. J Int Soc Prev Community Dent, 4, 145-8.

30.Donachie, M. A. and Walls, A. W. (1995). Assessment of tooth wear in an ageing population. J Dent, 23, 157-64.

31. Osborne, J. (1949). Abrasion resistance of dental materials. $\mathrm{Br}$ Dent J, 87, 10-2.

32. Slack, F. A., Jr. (1949). A preliminary method of testing abrasion hardness. J Am Dent Assoc, 39, 47-50.

33. Sexson, J. C. and Phillips, R. W. (1951). Studies on the effects of abrasives on acrylic resins. J Prosthet Dent, 1, 454-71.

34.Dobbs, H. E. and Abbott, D. J. (1968). Sensitive method for measuring the relative abrasiveness of dentifrices. J Dent Res, 47 , 1072-9.

35. Bull, W. H., Callender, R. M., Pugh, B. R. and Wood, G. D. (1986). The abrasion and cleaning properties of dentifrices. Br Dent J, 15, 331-337.

36. Heath, J. R. and Wilson, H. J. (1976). Abrasion of restorative materials by toothaste. J Oral Rehabil, 3, 121-38.

37. Grabenstetter, R. J., Broge, R. W., Jackson, F. L. and Radike, A. $\mathrm{W}$. (1958). The measurement of the abrasion of human teeth by dentifrice abrasives, a test utilizing radioactive technique. J Dent Res, 37, 1060-1068.

38. Harrington, E., Jones, P. A., Fisher, S. E. and Wilson, H. J. (1982). Toothbrush-dentifrice abrasion. A suggested standard method. $\mathrm{Br}$ Dent J, 153, 135-8.

39.Dickson, G. (1979). Physical and chemical properties and wear. J Dent Res, 58, 1535-43.

40. McCabe, J. F. and Smith, B. H. (1981). A method for measuring the wear of restorative materials in vitro. Br Dent J, 151, 123-6.

41. Atkinson, J. T., Groves, D., Lalor, M. J., Cunningham, J. and Williams, D. F. (1982). The measurement of wear in dental restoration using Laser Dual - Source contouring. Wear, 76, 91104.

42. Harrison, A. and Jagger, D. C. (1997). An in vitro investigation of the abrasive qualities of a selection of denture-cleaning pastes on poly(methyl methacrylate) denture base material. Prim Dent Care, 4, 21-4.

43. Schirrmeister, J. F., Huber, K., Hellwig, E. and Hahn, P. (2006). Two-year evaluation of a new nano-ceramic restorative material. Clin Oral Investig, 10, 181-6.

44. Reis, K. R., Bonfante, G., Pegoraro, L. F., Conti, P. C., Oliveira, P. C. and Kaizer, O. B. (2008). In vitro wear resistance of three types of polymethyl methacrylate denture teeth. J Appl Oral Sci, 16, 176-80

45. Cao, L., Zhao, X., Gong, X. and Zhao, S. (2013). An in vitro investigation of wear resistance and hardness of composite resins. Int J Clin Exp Med, 6, 423-30.

46. Oilo, G., Dahl, B. L., Hatle, G. and Gad, A. L. (1987). An index for evaluating wear of teeth. Acta Odontol Scand, 45, 361-5.

47. Fares, J., Shirodaria, S., Chiu, K., Ahmad, N., Sherriff, M. and Bartlett, D. (2009). A new index of tooth wear. Reproducibility and application to a sample of 18- to 30-year-old university students. Caries Res, 43, 119-25.

48. Chadwick, R. G., McCabe, J. F., Walls, A. W., Mitchell, H. L. and Storer, R. (1991). Comparison of a novel photogrammetric technique and modified USPHS criteria to monitor the wear of restorations. J Dent, 19, 39-45.

49. Carlsson, G. E., Johansson, A. and Lundqvist, S. (1985). Occlusal wear. A follow-up study of 18 subjects with extensively worn dentitions. Acta Odontol Scand, 43, 83-90.

50. Ohlmann, B., Trame, J. P., Dreyhaupt, J., Gabbert, O., Koob, A. and Rammelsberg, P. (2008). Wear of posterior metal-free polymer crowns after 2 years. J Oral Rehabil, 35, 782-8.

51.Ekfeldt, A. and Oilo, G. (1990). Wear of prosthodontic materials-an in vivo study. J Oral Rehabil, 17, 117-29.

52.Etman, M. K., Woolford, M. and Dunne, S. (2008). Quantitative measurement of tooth and ceramic wear: in vivo study. Int $J$ Prosthodont, 21, 245-52.

53. Suputtamongkol, K., Anusavice, K. J., Suchatlampong, C., Sithiamnuai, P. and Tulapornchai, C. (2008). Clinical performance 
and wear characteristics of veneered lithia-disilicate-based ceramic crowns. Dent Mater, 24, 667-73.

54. Ohlmann, B., Trame, J. P., Dreyhaupt, J., Gabbert, O., Koob, A. and Rammelsberg, P. (2008). Wear of posterior metal-free polymer crowns after 2 years. J Oral Rehabil, 35, 782-8.

55.Etman, M. K., Woolford, M. and Dunne, S. (2008). Quantitative measurement of tooth and ceramic wear: in vivo study. Int $J$ Prosthodont, 21, 245-52.

56.Lambrechts, P., Braem, M., Vuylsteke-Wauters, M. and Vanherle, G. (1989). Quantitative in vivo wear of human enamel. J Dent Res, $68,1752-4$

57.DeLong, R., Sasik, C., Pintado, M. R. and Douglas, W. H. (1989). The wear of enamel when opposed by ceramic systems. Dent Mater, 5, 266-71.

58. Albashaireh, Z. S., Ghazal, M. and Kern, M. (2010). Two-body wear of different ceramic materials opposed to zirconia ceramic. $J$ Prosthet Dent, 104, 105-13.

59. Ohlmann B., Trame JP. and Dreyhaupt J., et al. (2008). Wear of posterior metal-free polymer crownsafter 2 years. J Oral Rehabil, 35, 782-788.

60. Alarcon, J. V., Engelmeier, R. L., Powers, J. M. and Triolo, P. T. (2009). Wear testing of composite, gold, porcelain, and enamel opposing a removable cobalt-chromium partial denture alloy. $J$ Prosthodont, 18, 421-6.

61.Yu, H., Wegehaupt, F. J., Wiegand, A., Roos, M., Attin, T. and Buchalla, W. (2009). Erosion and abrasion of tooth-colored restorative materials and human enamel. J Dent, 37, 913-22.

62. Al-Omiri, M. K., Harb, R., Abu Hammad, O. A., Lamey, P. J., Lynch, E. and Clifford, T. J. (2010). Quantification of tooth wear: conventional vs new method using toolmakers microscope and a three-dimensional measuring technique. J Dent, 38, 560-8.

63.Liu, B., Zhang, M., Chen, Y. and Yao, Y. (2014). Tooth wear in aging people: an investigation of the prevalence and the influential factors of incisal/occlusal tooth wear in northwest China. BMC Oral Health, 14, 65.

\section{Citation:}

Mukatash Nimri E. G. Wear mechanisms and wear investigations of dental materials; a review of the literature. Oral Biol Dent. 2015; 3:4.

http://dx.doi.org/10.7243/2053-5775-3-4 